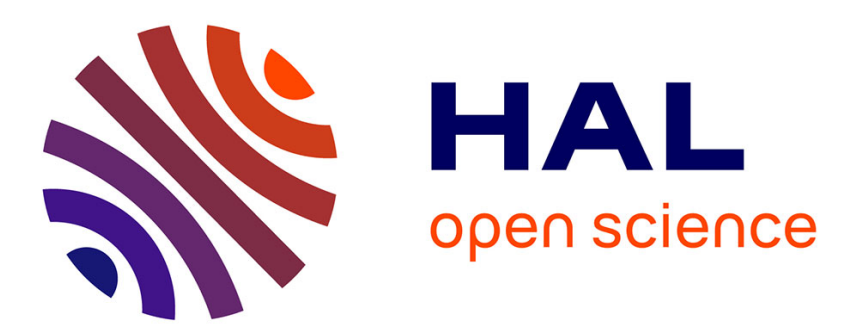

\title{
Design of a bio-inspired controller for dynamic soaring in a simulated uav
}

Renaud Barate, Stephane Doncieux, Jean-Arcady Meyer

\section{To cite this version:}

Renaud Barate, Stephane Doncieux, Jean-Arcady Meyer. Design of a bio-inspired controller for dynamic soaring in a simulated uav. Bioinspiration and Biomimetics, 2006, 1 (3), pp.76-88. 10.1088/1748-3182/1/3/002 . hal-02986348

\section{HAL Id: hal-02986348 \\ https://hal.science/hal-02986348}

Submitted on 2 Nov 2020

HAL is a multi-disciplinary open access archive for the deposit and dissemination of scientific research documents, whether they are published or not. The documents may come from teaching and research institutions in France or abroad, or from public or private research centers.
L'archive ouverte pluridisciplinaire HAL, est destinée au dépôt et à la diffusion de documents scientifiques de niveau recherche, publiés ou non, émanant des établissements d'enseignement et de recherche français ou étrangers, des laboratoires publics ou privés. 


\title{
Design of a bio-inspired controller for dynamic soaring in a simulated UAV
}

\author{
Renaud Barate, Stéphane Doncieux and Jean-Arcady Meyer \\ Université Pierre et Marie Curie - Paris 6, UMR 7606, AnimatLab/LIP6, 8 rue du \\ Capitaine Scott, Paris, 75015 France \\ E-mail: Renaud.Barate@ensta.fr, Stephane.Doncieux@lip6.fr, \\ Jean-Arcady.Meyer@lip6.fr
}

\begin{abstract}
This article is inspired by the way birds like albatrosses are able to exploit wind gradients at the surface of oceans for staying aloft during very long periods while minimizing their energy expenditure. The corresponding behaviour has been partially reproduced here via a set of Takagi-Sugeno-Kang (TSK) fuzzy rules controlling a simulated glider. First, such rules were hand-designed. Then, the rules were optimized with an evolutionary algorithm that improved their efficiency at coping with challenging conditions. Finally, the robustness properties of the generated controller were assessed with a view to its applicability to a real platform.
\end{abstract}

Keywords: Dynamic soaring, UAV, fuzzy rules, evolutionary algorithm.

This article has been published in Bioinspiration \& Biomimetics journal under the reference:

Renaud Barate, Stéphane Doncieux and Jean-Arcady Meyer. "Design of a bioinspired controller for dynamic soaring in a simulated unmanned aerial vehicle". Bioinspir. Biomim. 1 (2006) 76-88.

Bioinspiration \& Biomimetics copyright 2006 IOP Publishing Ltd. 


\section{Introduction}

Although designing Unmanned Aerial Vehicles (UAV) represents a great challenge for engineers because such platforms have to face complex and dynamic environments, numerous research efforts have been devoted to this endeavour and it has now become relatively easy to build autonomous flying robots, even with off-the-shelf components [1]. But the decisional autonomy of these platforms is still limited to a capacity to follow a given trajectory defined by a set of GPS waypoints. For lots of applications, a higher degree of autonomy is required, that would make it possible to give a robot watching over forest fires, for instance, a simple order like "stay over this area". This would entail providing the robot with a map of its environment and with the capacity of self-localizing within this map, but would avoid the necessity of pre-defining a series of waypoints to be followed. More importantly, such an approach would afford the robot the possibility of autonomously and opportunistically choosing its trajectory, so as to spare its energy consumption, a major issue for current UAV technology. Indeed, small-scale fixed-wing UAV - with wingspans less than two meters - currently exhibit an energy autonomy of one or two hours because they are committed to permanent use of their motors. If one could find a way to exploit the environment more efficiently, this autonomy could be widely expanded. To this end, nature is a good source of inspiration as lots of energy-saving strategies are exploited by birds.

Indeed, some birds are able to fly for very long periods. Albatrosses, for instance, can spend days in the air without touching the ground. They can reach such a performance because they are able to remain aloft without flapping their wings, mainly by exploiting wind gradients, thus saving precious energy. Likewise, birds of prey like eagles gain altitude by turning inside thermals, and mountain birds like jackdaws exploit slope-winds to fly without flapping their wings. All these behaviours have been observed by biologists $[2,3,4,5]$ and exploited by humans to efficiently pilot gliders [6]. However, in the latter case, the glider is permanently controlled by the human pilot, and the implementation of energy-saving behaviours in autonomous flying robots has scarcely been attempted yet, with the notable exception of a recent work [7] on the exploitation of thermals. The corresponding robot flies until a thermal is found, and then remains inside it by turning round, thus gaining altitude.

This strategy is only one of those that can be deduced from animal behaviours. It belongs to the static soaring category because it exploits the air flowing upwards: to gain altitude, the robot "just" needs to remain inside the thermal. Another strategy, that belongs to the dynamic soaring category, exploits wind gradients. Here, there is no upward flow but a horizontal wind, the speed of which varies with altitude, as may be the case above the ocean or above a mountain slope. To exploit such circumstances and save energy, a bird or a glider must follow a cyclic trajectory, starting from a relatively high altitude and flying down, wind in the back. Before hitting the water or the ground, it must turn back sharply to face the wind, in order to exploit the speed attained during the dive and so gain altitude. When its relative speed becomes too slow, it must turn 
back again, wind in the back, and start another cycle. When this strategy is tightly followed, the bird or glider extracts energy from the wind gradient, and is thus able to reach the same altitude it started from (fig. 1).

Dynamic soaring has been studied from theoretical and empirical perspectives $[8,9,10]$. Experienced pilots have recently proved to be able to exploit dynamic soaring principles on a small-scale glider [8]. Open loop controllers exhibiting an optimal trajectory have been designed in simulation [11]. Preliminary work on closed loop control of this behaviour revealed the difficulty of their implementation [12].

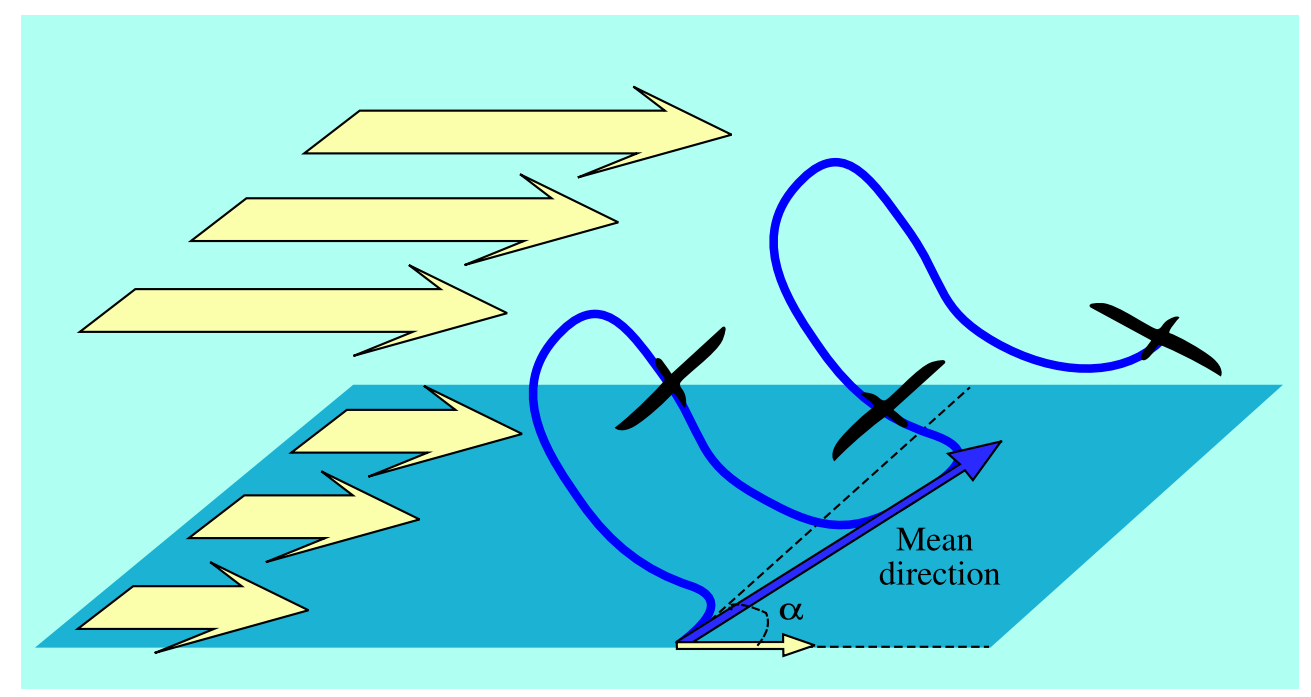

Figure 1. Trajectory used by the albatross for dynamic soaring. At the highest point of the trajectory, the albatros turns back to the wind and starts diving to gain speed. At the lowest point, the albatros sharply turns to face the wind and exploits the speed gained during the dive to gain altitude. At the end of this phase, the bird has reached the same altitude as that of its starting point. On average, the birds flies at a certain angle $\alpha$ with respect to the wind.

The objective of this research effort is to design such a closed loop controller. Experiments reported here have been done in simulation only, but with a view to assess the difficulty of implementation on a real platform.

This work is part of the ROBUR project that aims at building an artificial bird [13] within the framework of the animat approach, which draws inspiration from animal behaviour for the design of artificial autonomous agents able to "survive" or fulfil their mission in changing environments [14]. Ultimately, this project should produce a flapping-wing UAV able to take off, to land, to explore its environment and to manage its energy resources by exploiting aerology conditions or by getting back to a refilling station when required. The work reported here is the first step in this long journey. 


\section{Material and Methods}

\subsection{Flight model}

In order to test different controllers designed for dynamic soaring, we developed a specific flight simulator with a realistic aerodynamic model. This simulator is based on a perception-action control loop with a time step of $40 \mathrm{~ms}$, which means that 25 times per second the controller provides orders to the glider's actuators, according to the current state of its sensors. Wings are made of two panels with different dihedral angles - i.e. $2^{o}$ for the internal panel and $6^{\circ}$ for the external - to improve the stability of the glider.

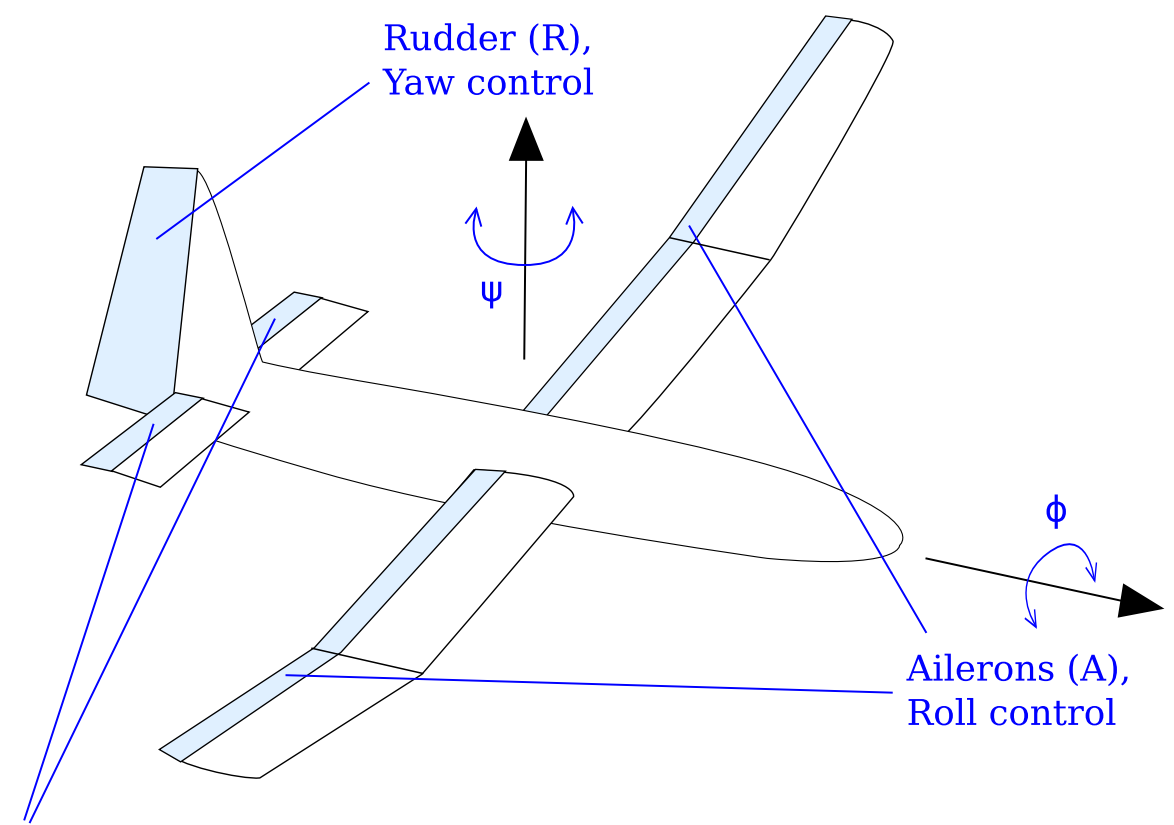

Elevators (E),

Pitch control

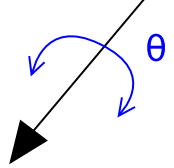

Figure 2. The different controls of the simulated glider : ailerons, elevators, and rudder.

The aerodynamic model integrates the forces exerted on the two panels that constitute a wing, and on the two perpendicular surfaces that characterize the tail (fig. 2). These forces depend on the characteristic curves that describe how the lift $(\mathrm{Cz})$ and drag $(\mathrm{Cx})$ coefficients vary with a panel's angle of attack [15]. The aerodynamic force exerted on each panel is calculated according to the following formula [16]: 


$$
\vec{F}_{A}=\left(\begin{array}{c}
-C X \\
0 \\
-C Z
\end{array}\right) \frac{\rho S V_{A}^{2}}{2}
$$

$\overrightarrow{F_{A}}$ being the aerodynamic force exerted on a given panel, $\rho$ the air density, $S$ the area of the panel, and $V_{A}$ the airspeed.

Aerodynamic forces on the body part of the glider are neglected here. The independent calculations of the forces on each panel allow the model to take implicitly into account some aerodynamic effects such as induced drag, environmental vortices, and wind gradients. Indeed, in a wind gradient, the airspeed of each panel will be different, and the resulting aerodynamic forces and momentums will reflect these differences. The characteristic curves of the panels are calculated to take into account the panel's aspect ratio. Figure 3 shows the resulting lift/drag ratio when the independant forces are integrated to calculate the aerodynamic force applied on the whole glider. However, it should be noted that the turbulences and vortices generated by the glider's geometry are not taken explicitly into account. Aerodynamic ground effect is also not modelled here. Although this choice can be discussed, we consider that the short period spent near the ground, and the high bank angle at this point of the trajectory, allow us to safely ignore this effect.

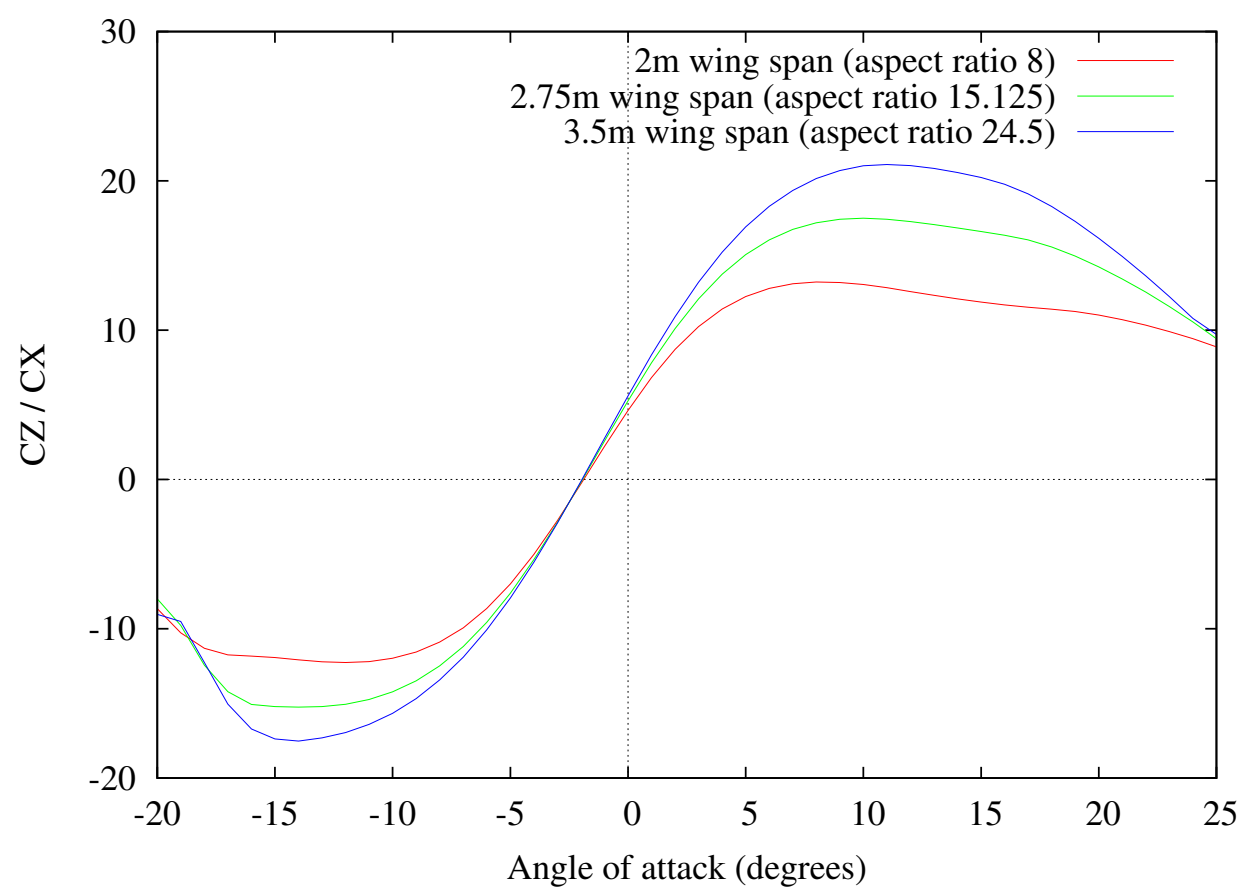

Figure 3. Variation of the lift/drag factor (CZ/CX) according to the angle of attack for the whole glider. Aspect ratios are taken into account in the calculation of the characteristic curves of each panel. The total wing area is held constant at $0.5 \mathrm{~m}^{2}$, no sideslip effect is present here. 
These aerodynamic forces are then integrated using classical solid body equations to determine the global linear and angular accelerations of the glider. Its weight is added to these forces and the system's state (position and velocity) is updated at each time-step.

In this simplified aerodynamic model, the controls of the glider are assumed to modify the angle of attack of its panels. Each swivelling control surface is thus characterized by an efficiency coefficient $k_{s i}$ with $i=0$ for the ailerons, $i=1$ for the elevator, and $i=2$ for the rudder. This coefficient is roughly equivalent to the proportion of the panel's surface it occupies. We chose:

- $k_{s 0}=-0.12$ (it has the same value for the internal and the external parts of a wing)

- $k_{s 1}=-0.15$

- $k_{s 2}=-0.5$

The amplitude of the controller's action on a particular control surface is represented by a value $d_{i}\left(d_{0}=A\right.$ corresponds to the aileron command, $d_{1}=E$ is the elevator command and $d_{2}=R$ is the rudder command, as explained later on) comprised between -1 and +1 , which is assumed to modify the angle of attack $\alpha_{R i}$ of the corresponding panel according to the formula: $\alpha_{M i}=\alpha_{R i}+d_{i} * k_{s i}$, where $\alpha_{M i}$ is the modified value.

Hopefully, this procedure provides a realistic enough simulation to make it possible to re-use the controllers thus generated on a real motorized glider. Be that as it may, although this simulation is based on a motorized glider geometry, the corresponding propulsion capacities are never used, and only the wind serves to move the UAV. Its physical characteristics are accordingly set to:

- Mass: $3.6 \mathrm{~kg}$

- Length: $1.5 \mathrm{~m}$

- Wing span: $2.75 \mathrm{~m}$ (variable in the experiment described in subsection 3.2)

- Total wing area: $0.5 \mathrm{~m}^{2}$ (70\% for the internal panel, $30 \%$ for the external panel)

- Wings sweep angle: $0^{\circ}$

- Wings dihedral angle: $2^{\circ}$ for the internal panel and $6^{\circ}$ for the external panel

- Wings twist angle: $2.5^{\circ}$

More details about the mass characteristics of the glider are presented in Appendix A.

\subsection{Wind model}

The vertical wind gradient that may be used for dynamic soaring above the ocean stretches over a thin layer (a few meters) in which the wind is slowed down by the interactions with the water surface. Observations made for winds of low to medium speed indicate that this gradient may be represented as a logarithmic function [17]. 
More precisely, we used the function described in [9] which defines the wind-speed $V_{W}$ at altitude $h$ as:

$$
V_{W}=V_{W_{R E F}} \frac{\log \left(h / H_{0}\right)}{\log \left(H_{R E F} / H_{0}\right)}
$$

$H_{R E F}$ is the reference altitude, i.e., 10 meters in this application.

$H_{0}$ is the altitude at which the wind-speed equals zero, here it is set to 0.03 meters.

$V_{W_{R E F}}$ is the wind-speed at reference altitude. Its default value is $20 \mathrm{~m} / \mathrm{s}$. This speed will occasionally be changed in some experiments described later.

The wind gradient described by this function is presented on Fig. 4.

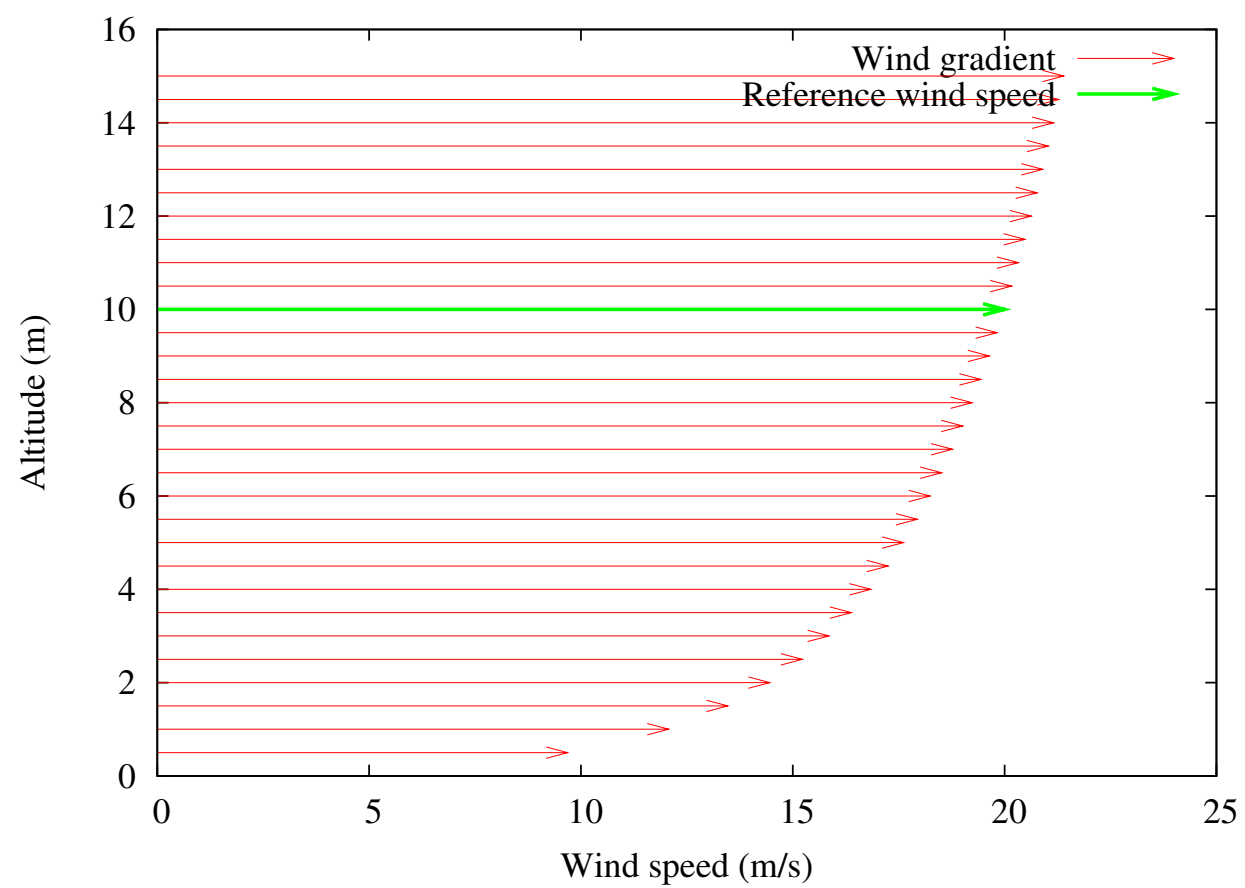

Figure 4. Wind-speed gradient used in the model

\subsection{Sensors and controls}

The sensory system of birds has not been thoroughly studied yet, but some relevant observations have been made [18]. Briefly, birds possess the same kind of visual receptors as humans (rods and cones) but they can discriminate colours better, see ultra-violet light, and perceive light polarization. They also have magnetic receptors, acting like compasses. Their tactile perception allows them to precisely sense pressure, pressure change, and pressure change acceleration, thus affording important information about air speed and air acceleration.

Nevertheless, because a long-term objective of this work is to apply it to a real glider, sensors as complex as those of birds weren't used here. Instead, we relied on 
more classical sensors to get the data necessary for flight control: an altimeter to get the glider's altitude, and an inertial measurement unit to get orientation angles. The variables measured by these sensors were:

- $z$, glider's altitude,

- $\psi$, glider's heading with respect to the wind

- $\theta$, glider's pitch angle with respect to an horizontal plane

- $\varphi$, glider's bank angle with respect to an horizontal plane.

We first considered that these sensors were perfect, in the sense that they were expected to provide exact values in real time. Later on in this paper, the influence of noisy sensors on the generated behaviour will be studied.

To control the glider, classical effectors were used, i.e., a pair of ailerons, a pair of elevators, and a rudder (fig. 2). As explained above, the corresponding variables were:

- $A$, aileron command comprised between -1 (maximum bank to the right) and +1 (maximum bank to the left);

- E, elevator command comprised between -1 (maximum upward) and +1 (maximum downward);

- $R$, rudder command comprised between -1 (maximum on the right) and +1 (maximum on the left).

\subsection{TSK fuzzy rules}

Controllers based on fuzzy rules have been successfully used for the control of several UAV systems $[19,20]$. Their main advantage is to call upon explicit rules, unlike neural networks whose inner workings may be difficult to decipher. They are particularly well suited for dealing with incomplete or uncertain data. The corresponding rules can be hand-designed by a human, or automatically generated by an evolutionary algorithm.

The principle of such fuzzy controllers consists in designing a set of rules that associate a particular action to a given sensory state. Such rules are made up with a condition part and an action part. The former may refer to fuzzy sets associated with each input, e.g., "IF $z$ is low AND $\dot{z}$ is greatly negative". The sum of the membership values of each input variable gives the strength of the rule. The latter may be fuzzy or not. Rules with fuzzy actions are called Mamdani rules [21], and sometimes require a tricky defuzzification procedure to generate the orders to be send to the system's actuators. Instead, in this work, we used Takagi-Sugeno-Kang (TSK) rules [22] for which the consequent of a rule is not a fuzzy set but a linear combination of the input variables. This method allows faster calculations than classical defuzzyfication methods. Thus, a typical TSK fuzzy rule would be for example "IF $z$ is low AND $\dot{z}$ is greatly negative THEN $E=0.25+0.5 z-0.25 \dot{z}^{\prime \prime}$.

It is also simple to make TSK fuzzy rules evolve via an evolutionary algorithm, as demonstrated, for instance, with the control of a real helicopter [23]. Fuzzy sets limits 
and rule coefficients being simple real numbers, it's easy to define the corresponding cross-over and mutation operators, a point that will be touched on later in this section.

\subsection{The controller's bio-inspired design}

In a first stage, we hand-designed a reference controller with rules inspired by observations of real albatrosses. This way, we checked that a TSK controller is well suited for this problem and we set a base for further evolutionary improvements.

In his 1982 observations [2], Pennycuick described the dynamic soaring behaviour in these terms:

A bird soaring across wind, along a wave, would from time to time turn into wind and pull up sharply, then turn at the top of the climb and glide off again across wind. The turns initiating and completing this manoeuvre were often abrupt and very steeply banked, up to $70^{\circ}$. This behaviour was seen in all the albatross species, and also in the giant petrel and white-chinned petrel.

Consequently, we decided to decompose the dynamic soaring behaviour of our controller into two phases:

- an ascending phase in which the bird faces the wind and gains altitude,

- a descending phase in which the bird is back to the wind and dives to gain speed.

More precisely, we wrote two sets of rules: one for turning toward the wind origin when the glider is low (ascending phase), and one for turning back to the wind when it is high (descending phase). The corresponding fuzzy sets were defined by ramp-type membership functions (Fig. 5).

The turns defined by these two sets of rules need to be very sharp, therefore they were triggered using the elevators with a very high bank angle. The rudder was used to prevent the glider from plunging right down to the sea. As for the ailerons, they were used to maintain the bank angle. With these principles, we wrote the first rules for the reference controller. Then we empirically improved the values defining the fuzzy sets, as well as other parameters of the rules, until we obtained an improved and coherent behaviour. Here are the details of the three hand-designed rules for turning back to the wind:

- When the glider is high, the elevators must be raised in order to trigger a sharp descent, but they also have to control the pitch angle to prevent the glider from diving too quickly. They also must get lowered at the end of the turn, when the glider is almost back to the wind. Therefore, the first rule is "If $z$ is high, $E=-0.6+0.01 \theta+0.006(\psi+180) "$.

- When the glider is high, it turns sharply to the right $\ddagger$. The rudder must then be put to the left in order to prevent the glider from diving due to the high bank

$\ddagger$ We arbitrarily chose this direction, with the consequence that the glider moved from north-west to south-east. 


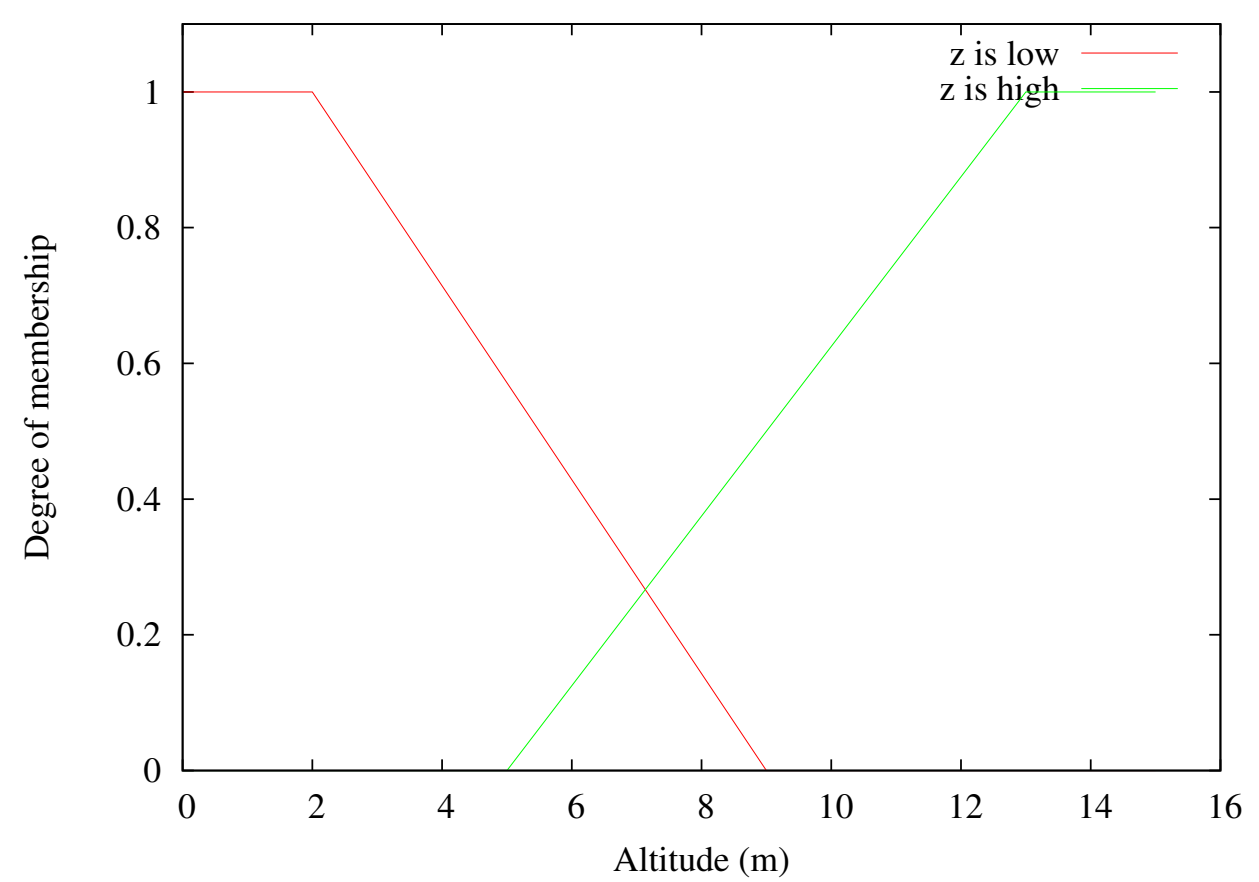

Figure 5. Fuzzy sets defined on variable $z$ (altitude). Two sets are defined, respectively for high and low altitudes, the corresponding degree of membership progressively changing according to the glider's altitude. In other words, when the latter is lesser than five meters, the system's altitude has more chances to be classified as "low" than as "high".

angle§. The corresponding $R$ value depends on the bank angle itself, and on the heading in order to trigger diving when the turn ends. Therefore, the second rule is "If $z$ is high, $R=-1.0+0.006(\psi+180)+0.01 \varphi$ ".

- When the glider is high, we use the ailerons to increase the bank angle for the turn to the right. The value for the ailerons depends on the bank angle because we want to stabilize it, and on the heading because we want to decrease the bank angle at the end of the turn. Therefore, the third rule is "If $z$ is high, $A=-1.0+0.006(\psi+180)+0.007 \varphi "$.

The three rules for turning toward the wind rely on the same principles:

- If $z$ is low, $E=-0.8+0.02 \theta+0.005(\psi+180)$;

- If $z$ is low, $R=0.006(\psi+180)+0.01 \varphi$;

- If $z$ is low, $A=0.006(\psi+180)+0.007 \varphi$.

The positions of the control surfaces in each phase of the trajectory are shown in figure 6. Here we assume that the wind blows from north to south. It should be mentioned that the rules just described allow dynamic soaring in one direction only,

$\S$ In this configuration, the rudder is almost horizontal and acts like the elevators in the glider's nominal position 
i.e., from the north-west to the south-east. To prompt flights from north-east to southwest, we just have to replace $\psi$ by $(360-\psi), \varphi$ by $-\varphi$ and to change the sign of the rules for $R$ and $A$. We will describe in section 3.3 some experiments we made to evolve controllers able to fly in different directions.

In fact, it appeared that this hand-designed reference controller exhibited the kind of behaviour we were interested in, but it was not really efficient. More specifically, it worked only when the wind-speed was high enough, and it failed to keep the glider aloft beyond four complete cycles. Nevertheless it constituted a good starting point for its improvement via an evolutionary algorithm, as described in the following section.

\subsection{Evolutionary optimization}

The goal of the evolutionary algorithm described here was to generate a more efficient and more robust soaring behaviour. This algorithm was initialized with the handdesigned rules of the reference controller just described.

The genome of each controller was represented by a vector of real variables, each number corresponding to a rule parameter, or to a boundary of the altitude fuzzy set. Each generation of controllers but the first contained 100 individuals, and the experiments involved 100 generations. The first generation contained 1000 individuals in order to increase the number of interesting controllers at the beginning of the evolutionary run, and thus to accelerate the convergence of the algorithm.

In each generation, the 20 best individuals were kept, while the other 80 individuals were deleted (980 in the first generation) and replaced by 80 new ones. The fitness criteria that were used depended on the experiments that were performed, and will be described in the next section. Each creation of a new individual was done in two steps: first a cross-over, then a mutation.

For the cross-over, two individuals were randomly selected from among the survivors of the previous generation. The probability of selection depended on individual rankings, individuals with higher fitnesses being chosen more often than those with lower fitnesses. Each gene of a new individual was then inherited from one of its parents with an equal probability.

Mutations consisted of slightly changing the value of each gene. The mutation of a gene value $\gamma$ was defined by:

$$
\gamma_{t+1}=\gamma_{t}+\mathcal{N}(0, \mu * \tau)
$$

where the function $\mathcal{N}(0, \mu * \tau)$ represents a normal distribution of zero mean and standard deviation $\mu * \tau$. $\mu$ is a mutation factor defined for each gene, and $\tau$ is an attenuation factor $\tau$ which decreases the amplitude of the mutations in the last generations. Methods for automatically adapting the mutation rate exist [24, 25], but the use of an attenuation factor, as done here, lead to quicker convergence than such alternative procedures.

The mutation factor $\mu$ was defined by: 


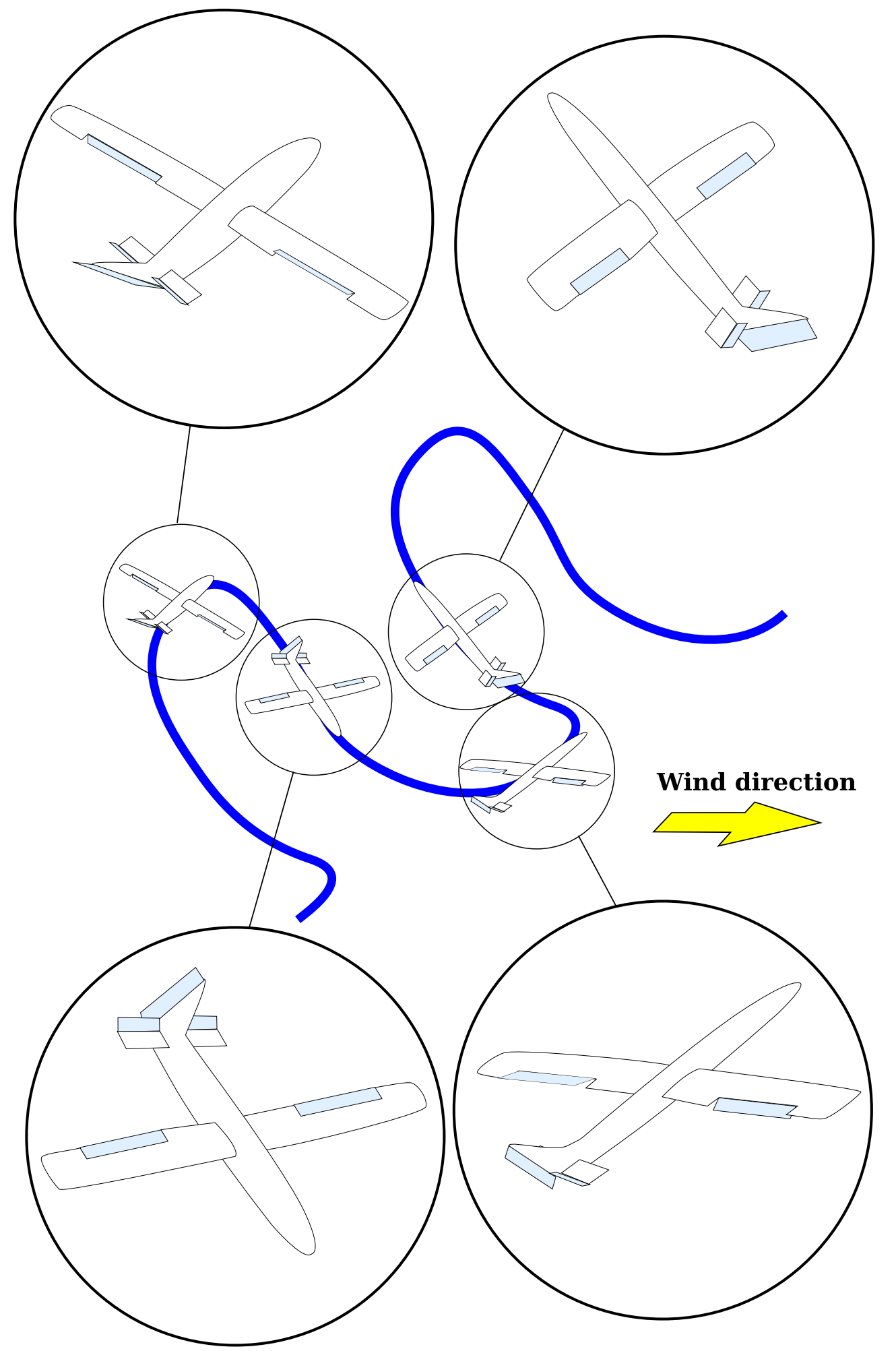

Figure 6. Glider's trajectory and position of its control surfaces in each phase. See text for details. 
- $\mu=0.1$ for genes corresponding to rule parameters,

- $\mu=1.0$ for genes corresponding to altitude fuzzy set boundaries.

The attenuation factor $\tau$ has been determined empirically. For generation $g$ it was defined by equation:

$$
\tau=\exp \left(\frac{-g}{20}\right)
$$

\section{Experiments and results}

\subsection{Low wind-speed conditions}

The first series of experiments consisted in using the evolutionary algorithm just described to generate controllers able to secure a dynamic soaring behaviour in lower wind-speed conditions than those required by the reference controller. To limit simulation time, we assessed the fitness of an individual by the minimal wind-speed that maintained it aloft for 1000 seconds, and tried to minimize this value.

For each individual, this process started with the nominal wind-speed to which the reference controller was adapted - i.e., $20 \mathrm{~m} / \mathrm{s}$ - and proceeded with a dichotomous search. Individuals that could not fly for the whole of the evaluation period, even with the reference wind speed, were ranked according to how long they stayed aloft.

For each generation, if the necessary wind-speed for the twentieth and less adapted individual was less than the current reference wind speed, the corresponding value became the new reference speed to be used for next generations. This procedure greatly accelerated the computations.

Figure 7 shows the results obtained along 100 generations. It appears that the best individual thus generated is able to exhibit a dynamic soaring behaviour with a wind-speed of only $9.4 \mathrm{~m} / \mathrm{s}$. By comparison, the minimum wind-speed needed by the albatross seems to be about $8.6 \mathrm{~m} / \mathrm{s}$ [9].

It is interesting to compare the trajectory used by the reference controller with the one used by the best evolved controller (Fig. 8 and 9). The first loses altitude in each cycle and ends up in the water after only four cycles. The second keeps a constant altitude at the top of each cycle and rapidly follows a periodical trajectory, although the wind-speed is twice lower.

Table 1 summarizes the differences between the hand-designed controller and the evolved one. These differences are neither negligible nor reflecting drastic changes. They suggest that the design of dynamic soaring controllers, like those considered here at least, is a difficult task, as small changes in the corresponding parameters may cause a glider to operate perfectly well, or to crash after a few cycles only. This remark probably explains why we never succeeded to evolve such controllers from scratch, and why they proved to be sensitive to turbulences and sensory noise, as mentioned in section 3.4 below. 


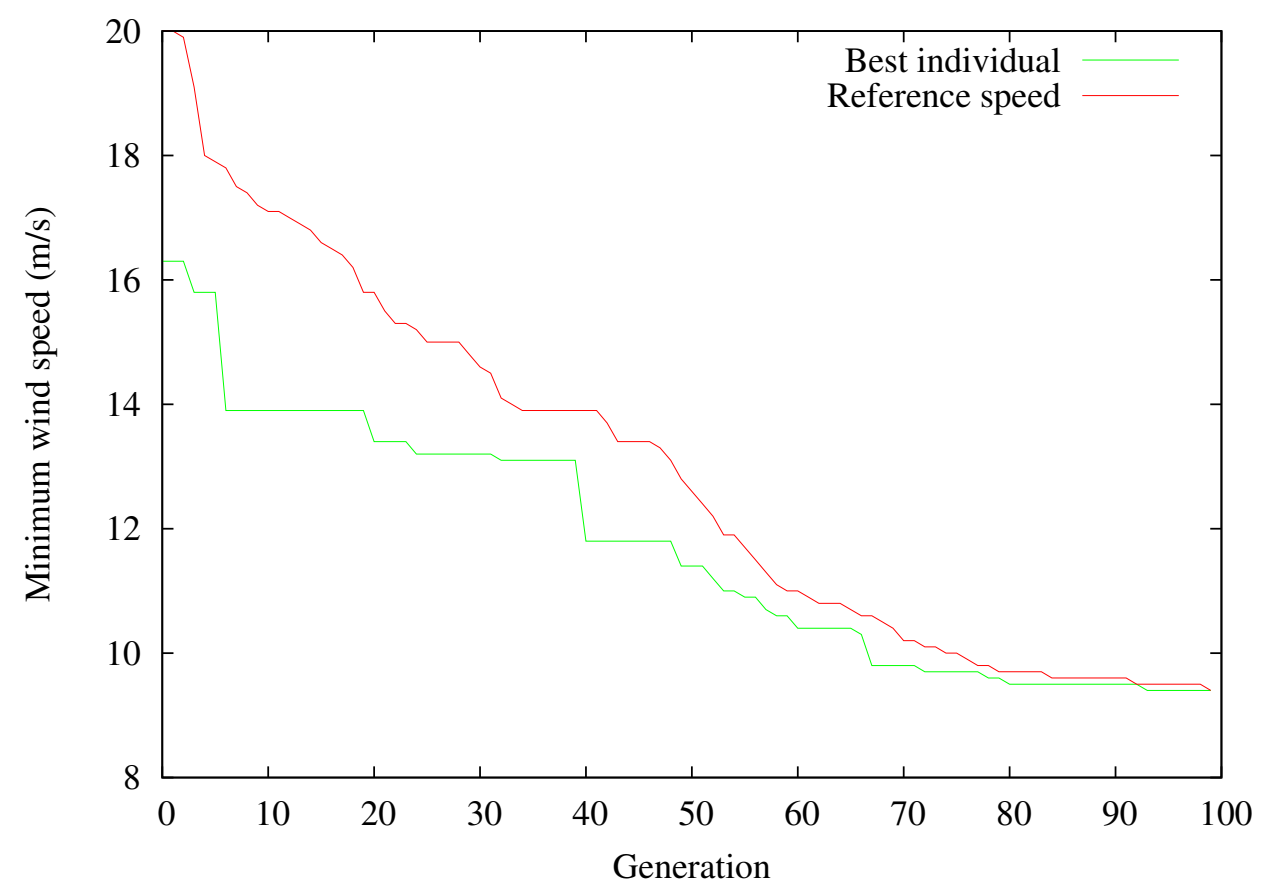

Figure 7. Evolution of the minimal wind-speed that secures dynamic soaring in the simulated glider
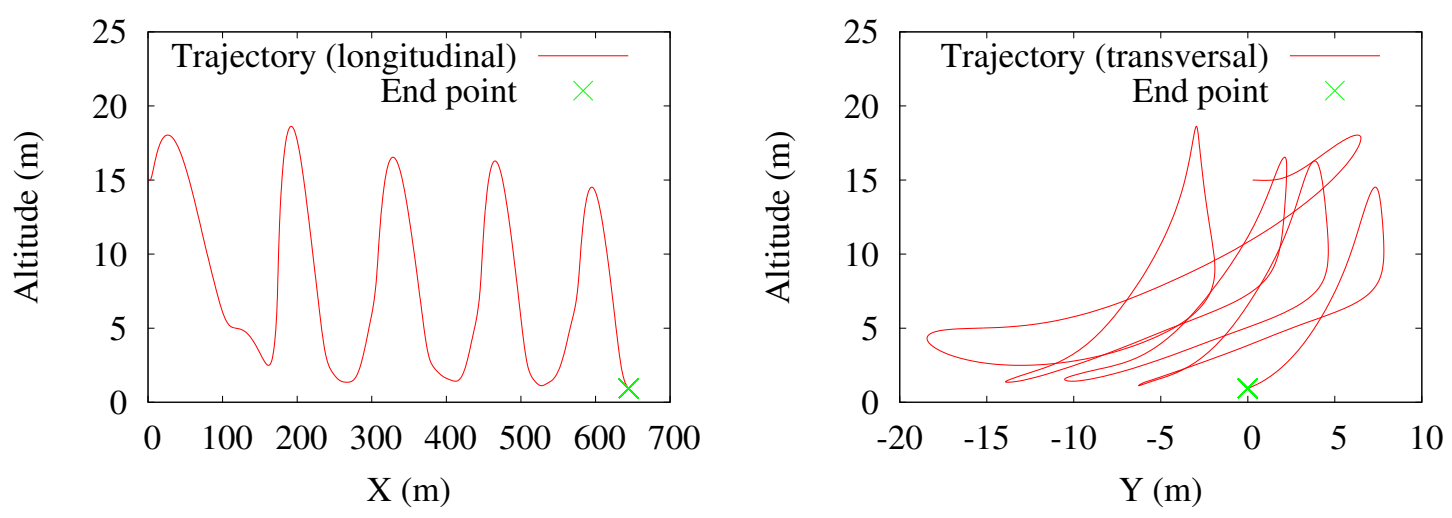

Figure 8. Longitudinal and transversal projections of the glider's trajectory with the reference controller (wind-speed : $20 \mathrm{~m} / \mathrm{s}$ ). The flight is not regular and ends after four cycles at the "End point".

\subsection{Wing aspect ratio}

The goal of this series of experiments was to evaluate the morphology of a real glider on which the dynamic soaring behaviour studied here could be implemented. To this end, we compared results obtained by changing the glider's wing aspect ratio $A R_{W}$, defined as the ratio of the wing span $S_{W}$ and the chord $C_{W}$ for a rectangular wing, or as the ratio of the squared wing span and the wing area $A_{W}$ for a wing of any shape (fig. 10): 

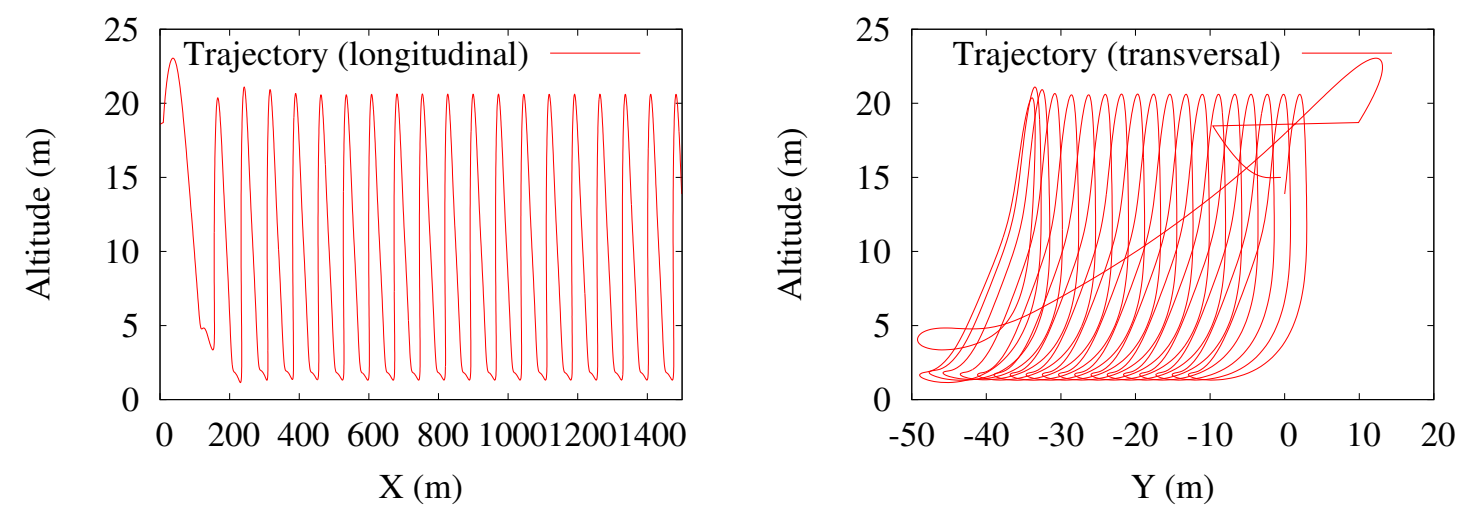

Figure 9. Longitudinal and transversal projections of the glider's trajectory with the best evolved controller (wind-speed : $10 \mathrm{~m} / \mathrm{s}$ ). The flight quickly becomes cyclic and the altitude at the top of each cycle remains constant.

\begin{tabular}{|c|c|c|}
\hline & Hand-designed controller & Evolved controller \\
\hline Fuzzy sets & & $3.095691 \rightarrow 11.452055$ \\
\hline $\mathrm{z}$ is high, Ramp bounds & $5.0 \rightarrow 13.0$ & $1.857289 \rightarrow 8.453340$ \\
\hline $\mathrm{z}$ is low, Ramp bounds & $2.0 \rightarrow 9.0$ & \\
\hline Rules & & $-0.599127+0.004392(\psi+180)+0.006740 \theta$ \\
\hline $\mathrm{z}$ is high, $\mathrm{E}=$ & $-0.6+0.006(\psi+180)+0.01 \theta$ & $-1.0508521 \varphi$ \\
\hline $\mathrm{z}$ is high, $\mathrm{G}=$ & $-1.0+0.006(\psi+180)+0.01 \varphi$ & $-1.056806+0.002087(\psi+180)+0.008521$ \\
\hline $\mathrm{z}$ is high, $\mathrm{A}=$ & $-1.0+0.006(\psi+180)+0.007 \varphi$ & $-0.831355+0.003803(\psi+180)+0.014658 \varphi$ \\
\hline $\mathrm{z}$ is low, $\mathrm{E}=$ & $-0.8+0.005(\psi+180)+0.02 \theta$ & $-1.288160+0.006382(\psi+180)+0.020173 \theta$ \\
\hline $\mathrm{z}$ is low, $\mathrm{G}=$ & $0.0+0.006(\psi+180)+0.01 \varphi$ & $0.000793+0.011099(\psi+180)+0.006601 \varphi$ \\
\hline $\mathrm{z}$ is low, $\mathrm{A}=$ & $0.0+0.006(\psi+180)+0.007 \varphi$ & $-0.002391+0.009162(\psi+180)+0.012029 \varphi$ \\
\hline
\end{tabular}

Table 1. Comparison between hand-designed and automatically-evolved rules.

$$
A R_{W}=\frac{S_{W}}{C_{W}}=\frac{S_{W} * S_{W}}{C_{W} * S_{W}}=\frac{S_{W}^{2}}{A_{W}}
$$

In these experiments, we increased the wing aspect ratio by increasing the wing span and decreasing the wing chord. The wing area and mass were held constant all the while. Again, an evolutionary approach was used to seek the lowest wind-speed compatible with dynamic soaring for a variety of aspect ratios. The corresponding results are shown in figure 11.

These results show that dynamic soaring can be efficiently performed for aspect ratios varying between 12 and 21. As a comparison, the aspect ratio of an albatross' wing roughly equals 18 [9]. The existence of a lower limit can be related to the fact that a low aspect ratio decreases the lift, and increases the drag of the wing. This explains why gliders and migratory birds have wings with high aspect ratios. As for the existence of an upper limit, it has to do with the nature of the trajectory used for dynamic soaring. Indeed, when the glider is near the water, it makes a sharp turn on the wing to face the wind. The bank angle is then very high, which means that a glider with a 2-meter wing span won't be able to get much lower than 1 meter before hitting the water. The wind gradient being more important in the first meters above water, 


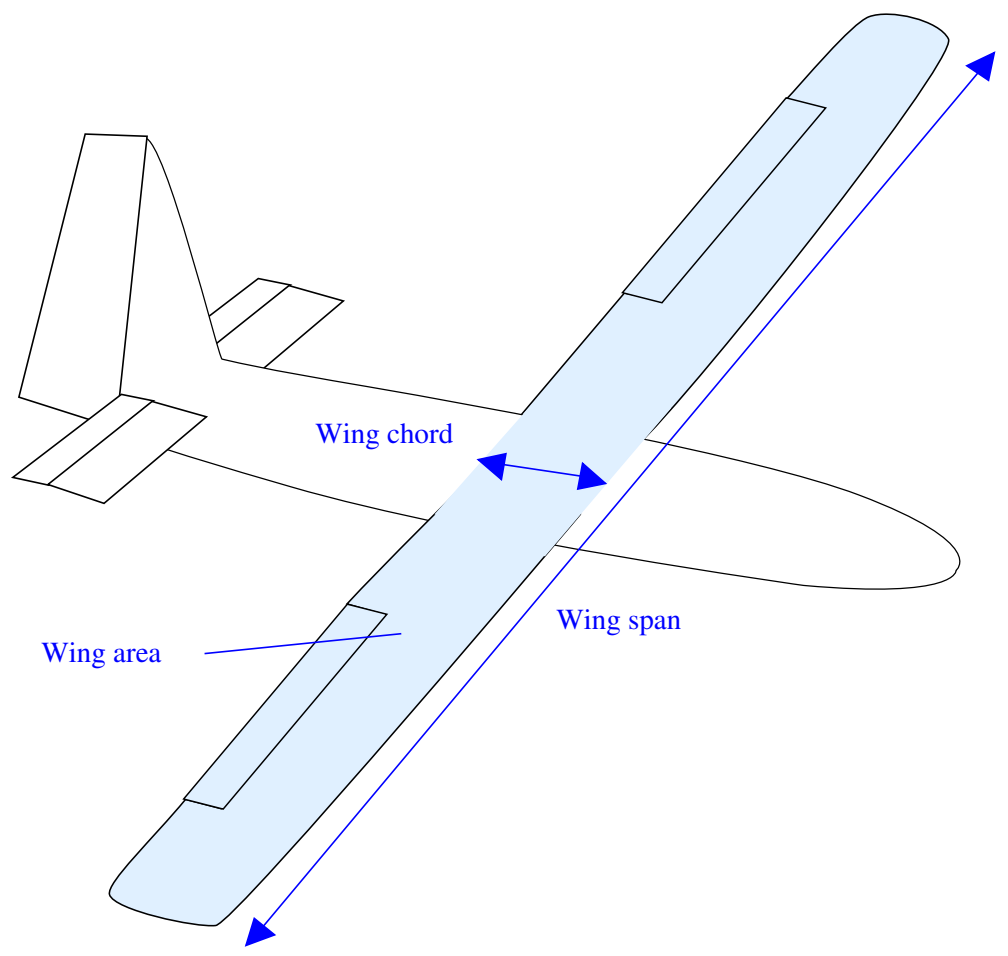

Figure 10. Characterization of the wing span, the wing chord, and the wing area that serve to calculate the wing's aspect ratio.

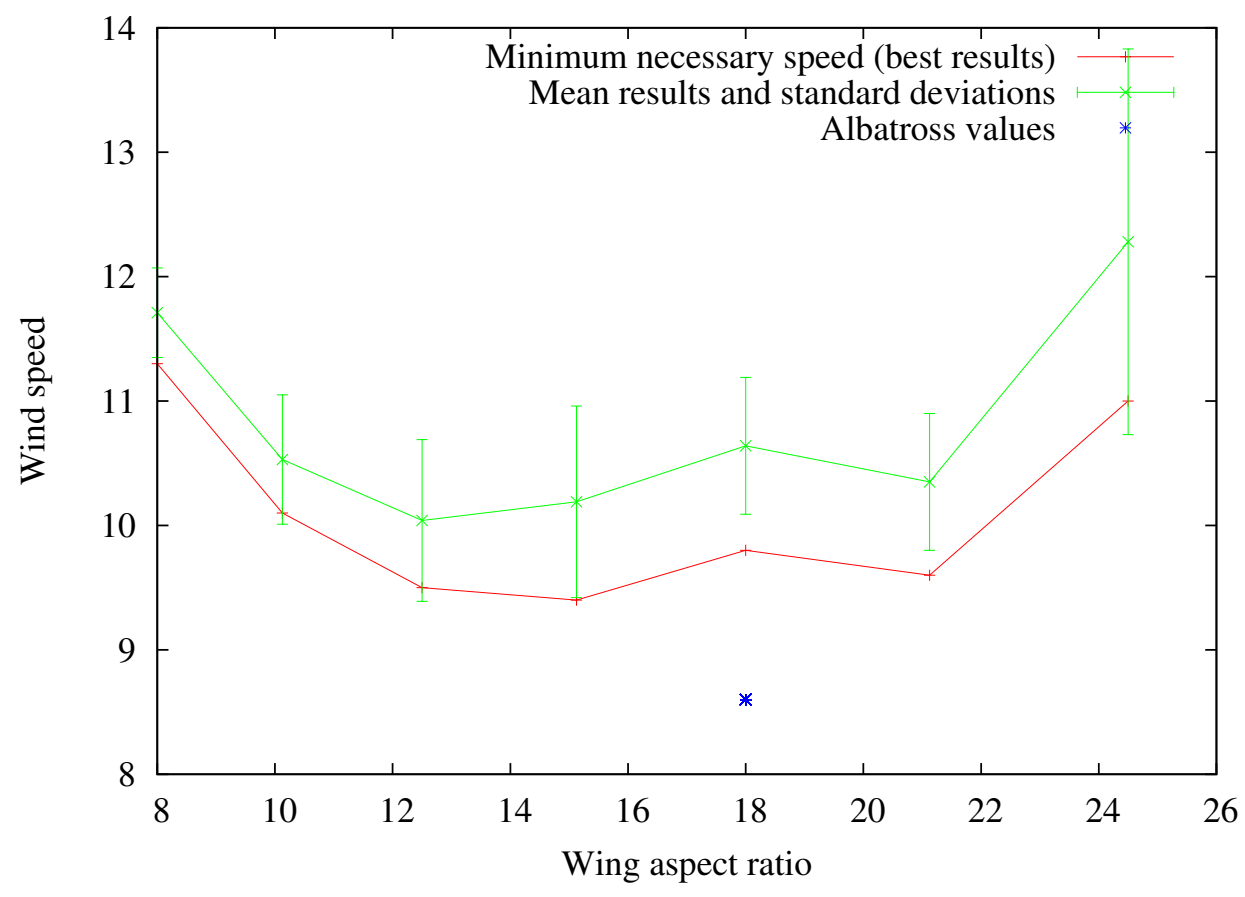

Figure 11. Minimum necessary wind-speed as a function of wing aspect ratio. Efficient dynamic soaring, i.e., under slow wind-speed conditions, can be performed for wing aspect ratios varying between 12 and 21 . 
a high aspect ratio can prevent efficient dynamic soaring, as it will prevent the glider from going low enough to take advantage from the steepest part of the gradient\|.

\subsection{Soaring direction}

In the experiments just described, the goal for the glider was merely to stay aloft for the longest time, and the average direction of the glider was not taken into account in the fitness. In fact, the reference controller generates a trajectory whose overall direction is oriented from north-west to south-east with a wind blowing from the north. Here, we wanted to assess the possibility of evolving controllers able to move the glider in different directions, against the wind for instance.

To this end, we changed the fitness function in order to select individuals that flew in a given direction. More precisely, the corresponding fitness function was the difference between the glider's mean heading and the target's heading, the goal being to minimize this function. The heading variable $\psi$ being defined as the angle between the wind and the glider's heading, the fitness function $f($ ind $)$ was set to $f($ ind $)=a b s\left(\psi_{\text {mean }}-\psi_{\text {target }}\right)$. For each generation, we selected the individuals whose headings were the closest to the target's one.

Only two experiments were made in order to determine the full range of directions that could be achieved with the kind of controllers studied here. The first one sought controllers generating flights against-the-wind (target heading $=180^{\circ}$ ), while the second one sought controllers generating back-to-the-wind flights (target heading $=0^{\circ}$ ). These experiments made it possible to determine the minimum and maximum angles relative to the wind that delimit the directions in which the glider can fly.

Results obtained during the first experiment indicate that the maximum angle between the glider's heading and the wind's origin was $53^{\circ}$. In the second experiment, the minimum angle was $8^{\circ}$.

Inasmuch as symmetrical flying-angle values may be attained by making appropriate changes in a controller's fuzzy rules, it appears that angles between 8 and $-8^{\circ}$ can be reached by adequately switching the desired direction between these two values $\Phi$. It may be concluded from this section that the full range of flying directions afforded by the variety of controller investigated in this work is $\left[-53^{\circ} ; 53^{\circ}\right]$ (Fig. 12).

To appreciate the significance of these results, we thoroughly examined the flying behaviours generated by three evolved controllers: the one corresponding to a mean heading of $53^{\circ}$ - the maximum value -, the one corresponding to a mean heading of $8^{\circ}$ - the minimum value -, and one corresponding to a mean value of $30^{\circ}$ - arbitrarily chosen in the preceding interval. The details of the rules that correspond to these three controllers are given in Appendix B.

\| As our evolved controller brings the glider down to $1.32 \mathrm{~m}$, one of its wings is approximately $0.15 \mathrm{~m}$ above the water during the sharp turn (wing length of 1.375 and bank angle of $58^{\circ}$ ).

I if the glider spends $50 \%$ of its trajectory oriented toward $8^{\circ}$ and $50 \%$ oriented toward $-8^{\circ}$, the glider direction will be $0^{\circ}$ on average. 


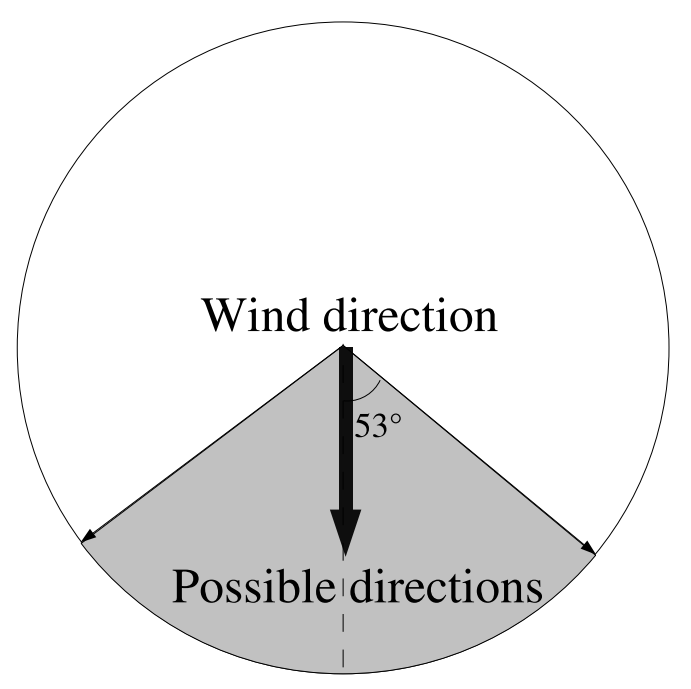

Figure 12. The range of average directions toward which a glider can fly using the controllers evolved in this work.

It thus appears that these controllers implement different strategies. In particular, the $53^{\circ}$ controller oscillates less than the others (Fig. 13b, 13c, 13d) and remains approximately between 0 and 10 meters whereas other controllers reach far higher altitudes (Fig. 13a). The movement direction imposed by the $53^{\circ}$ controller is almost always further from the wind than those corresponding to the other controllers, even reaching a peak at $90.5^{\circ}$ (Fig. 13e). The movement direction angle is greater in the lower part of the cycle than in the higher part for all three controllers. This is particulary true with the $53^{\circ}$ controller that makes the glider fly lower than with the two other controllers : this way, it avoids being carried by the wind which is stronger at higher altitudes.

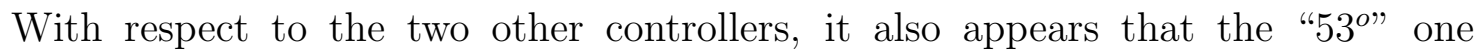
generates greater forces serving to accelerate along the lateral axis during the period when the altitude is high (table 2). Such strategy increases the lateral speed of the glider during the first cycles, with the consequence that it also increases the drag during this critical phase that makes it possible to gain kinetic energy (Fig. 14 and 15). As a result, the farther the glider is relatively to the wind direction, the more energy it looses. According to our results, $53^{\circ}$ seems to be the greatest angle for which an equilibrium can be found, at least in the experimental setup used here.

These results stress the limits of our approach focussed on dynamic soaring only. 


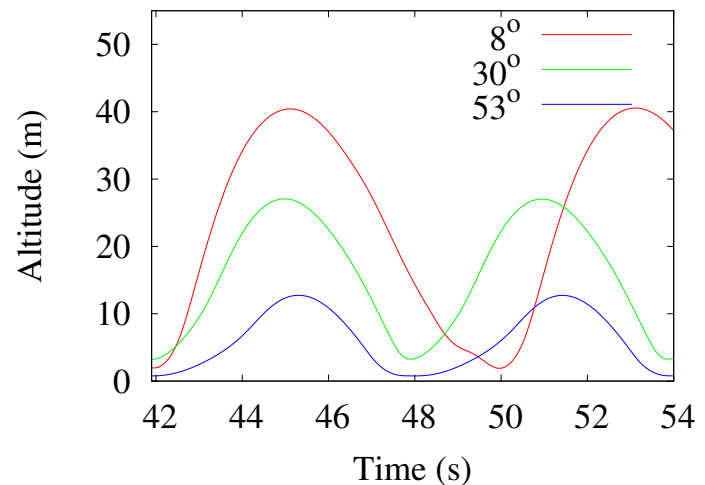

(a)

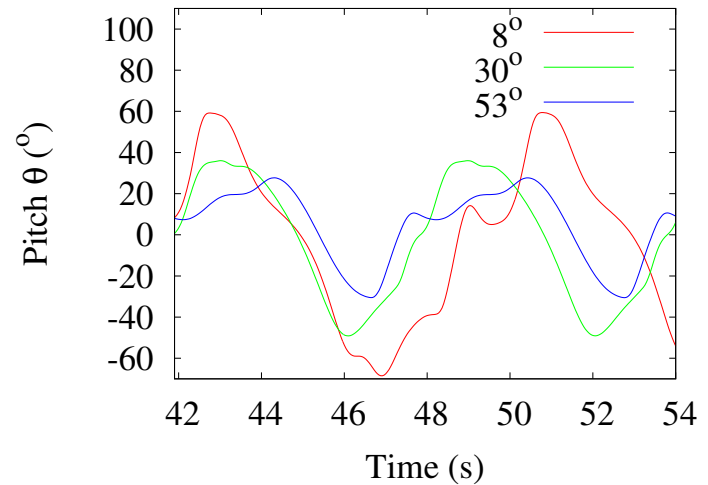

(c)

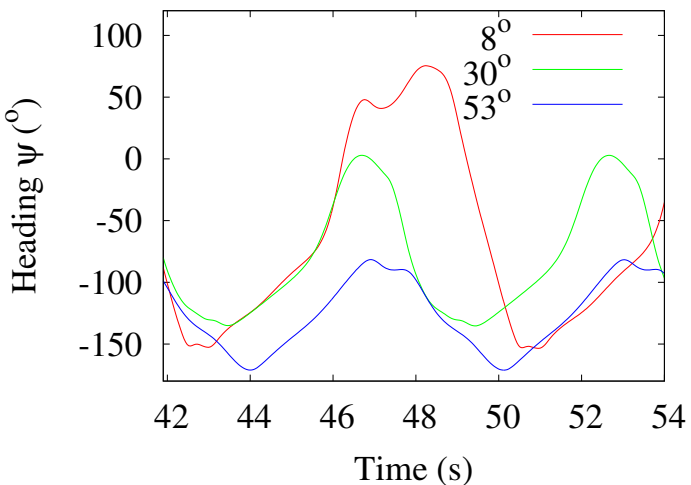

(b)

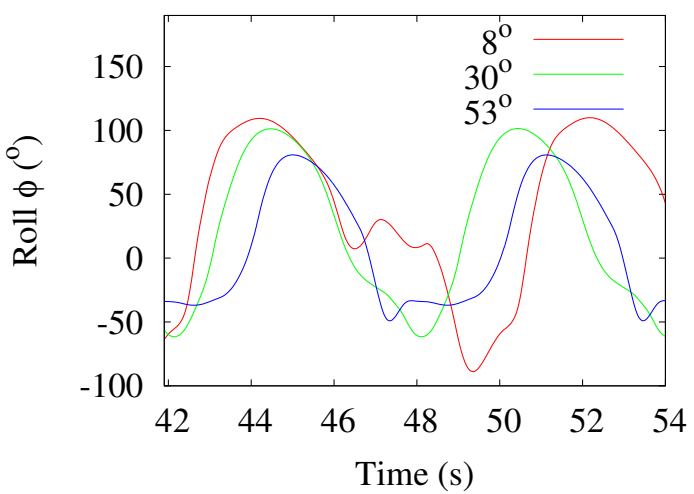

(d)

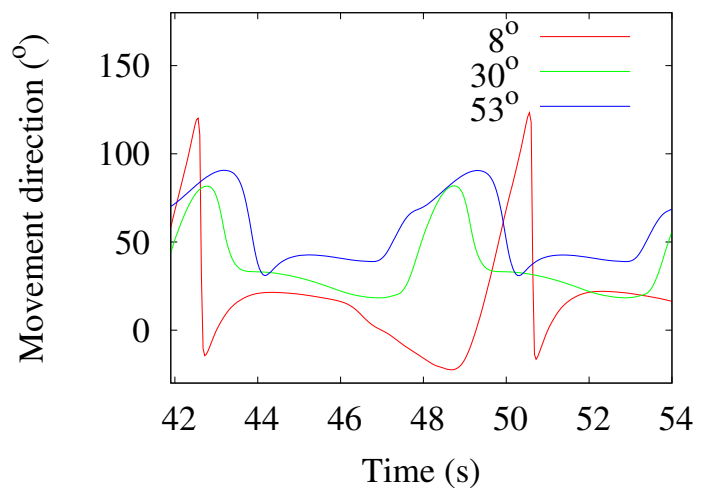

(e)

Figure 13. Altitude (a), orientation angles (heading (b), pitch (c) and roll (d)) and movement direction (e) of a glider flying toward three different mean directions : $8^{\circ}$, $30^{\circ}$ and $53^{\circ}$ relative to the wind. Data for $8^{\circ}$ and $30^{\circ}$ have been respectively shifted by $2.4 \mathrm{~s}$ and $1.5 \mathrm{~s}$, to synchronize the beginning of each cycle. 


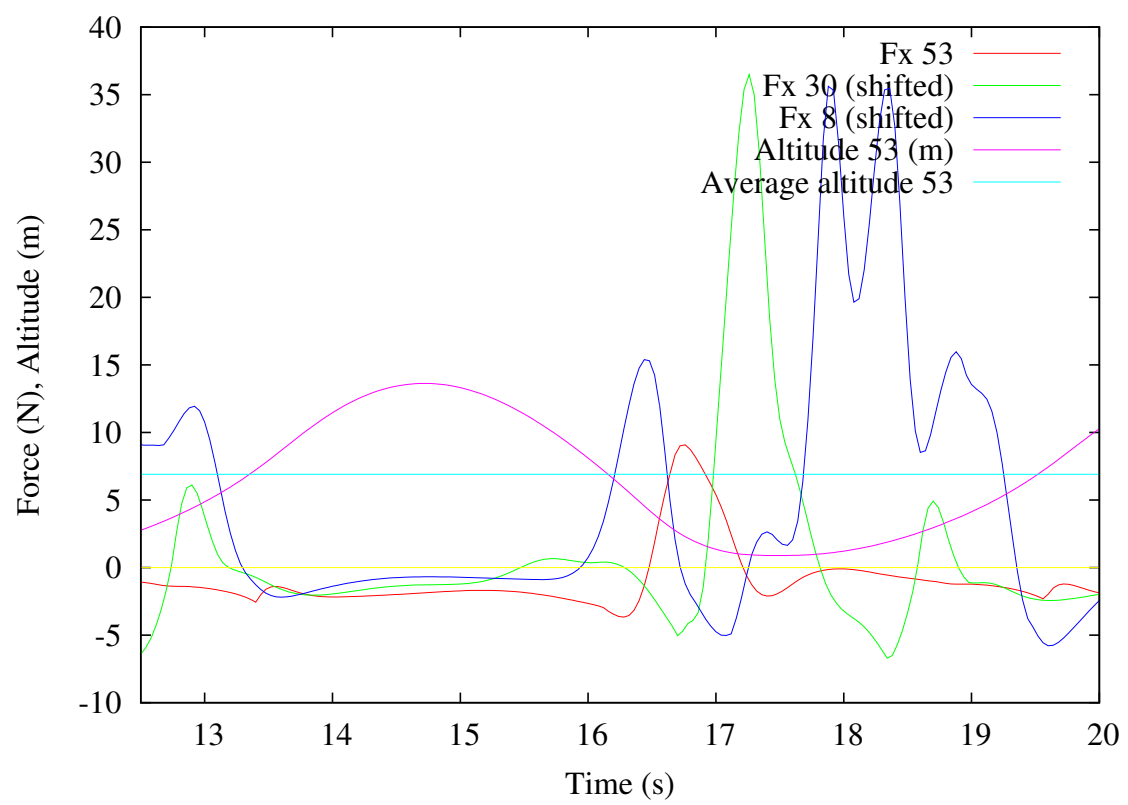

Figure 14. Resultants of aerodynamic forces projected on the longitudinal axis of the glider $\left(F_{x}\right) . F_{x}$ is lesser with the $53^{\circ}$ controller than with the two others. In particular, it is negative and, most of the time, smaller than the others when $z$ is greater than $z_{\text {avg. }}$.

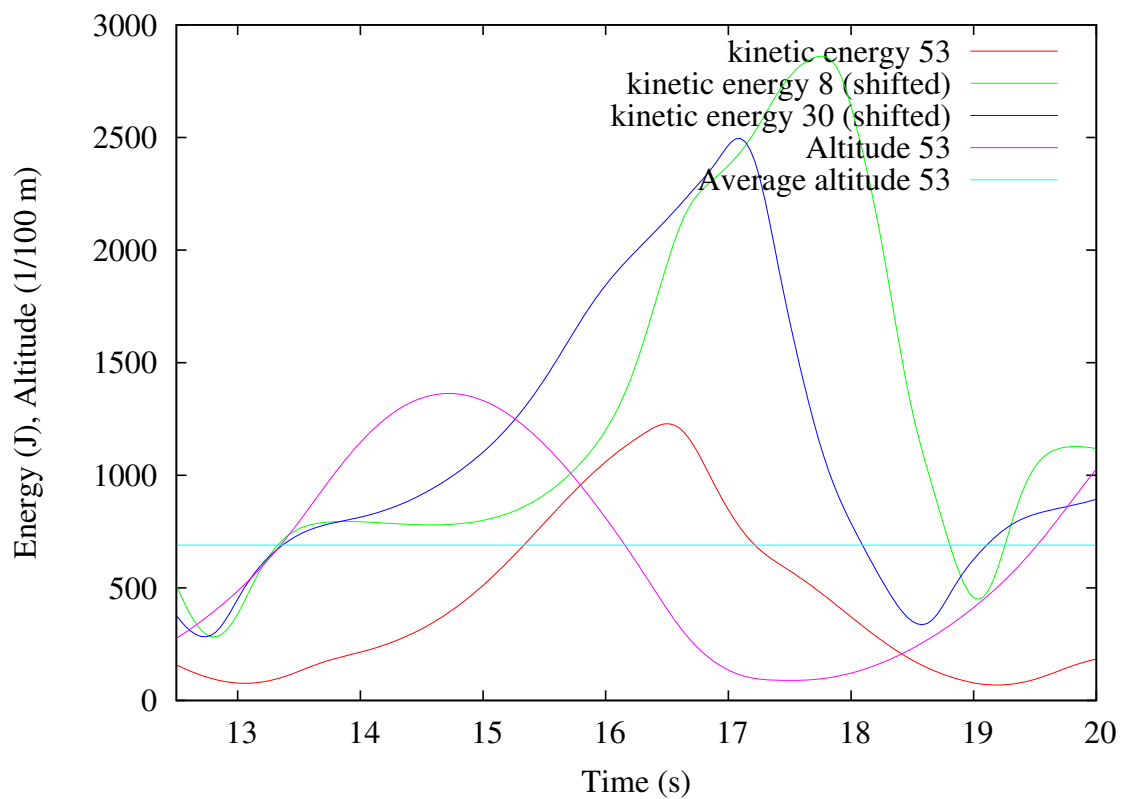

Figure 15. Kinetic energy variations for controllers generating flights in different directions. $6.9 \mathrm{~m}$ being the average value of altitude corresponding to the $53^{\circ}$-controlled glider, the period when altitude exceeds this value corresponds to the acceleration phase of the glider. This acceleration is lesser for the $53^{\circ}$ controller than for the other two. Kinetic energies corresponding to the $30^{\circ}$ and $8^{\circ}$ controllers are shifted in time by resp. $1.1 \mathrm{~s}$ and $1.8 \mathrm{~s}$, in order to synchronize the three cycles. 


\begin{tabular}{|c|c|c|c|}
\hline & $53^{\circ}$ & $30^{\circ}$ & $8^{\circ}$ \\
\hline Average $F y_{\text {abs }}(\mathrm{N})$ & 0.69 & 0.34 & -0.08 \\
\hline Average altitude $z_{\text {avg }}(\mathrm{m})$ & 6.9 & 15.5 & 19.6 \\
\hline Average $F y_{\text {abs }}(N)$ & & & \\
for $z>z_{\text {avg }}$ & 14.9 & 3.98 & -3.79 \\
for $z<z_{\text {avg }}$ & -12.19 & -3.6 & 2.9 \\
\hline
\end{tabular}

Table 2. Average value of projection on the Y-axis of the sum of aerodynamic forces in the absolute frame. These values correspond to the first 60 s of a test flight and accordingly mostly characterize the transient phase. At steady state, the average value of $F y_{a b s}$ is null, as the lateral speed is constant.

Indeed, the glider is unable to follow a trajectory that is, on average, directed against the wind, a performance of which albatrosses are perfectly capable. This is due to the fact that these birds may use other means than dynamic soaring for flying without self-propulsion. For instance, Pennycuick observed albatrosses flying without flapping their wings with a very low wind, or even with no wind at all [2] and, because dynamic soaring is impossible in these conditions, he suggested that another source of energy is used by these birds:

The observations suggest $[. .$.$] that in practice most of the energy for windward$ pullups comes from slope lift [...] and relatively little from the wind gradient. The wind gradient may supply relatively more energy in downwind flight, but no direct observations were obtained to support this.

It would therefore be necessary to model such slope currents along the waves to be able to reproduce the trajectories of albatrosses more precisely.

\subsection{Control robustness}

Other experiments were run to test the robustness of the controllers developed here. More precisely, we evaluated their robustness to variations in initial conditions, to wind turbulences, and to sensory noise. It should be noted that these experiments were not designed to assess a controller's robustness to particular conditions, which would require a much more realistic environmental model, but rather to evaluate the genericity of the evolved controllers. We only look for an answer to the question "Are these controllers able to cope with slight changes in the environment?". Answers to the questions "Are these controllers able to cope with a real environment ?" and "Are these controllers able to adjust their behaviour depending on the environment ?" are, of course, related to this study, but they will be investigated thoroughly in a future work.

Concerning robustness to initial conditions, we evolved controllers as we did in the first experiment, but starting with a wider range of altitude, heading and relative speed conditions. These conditions were set at random in the following ranges: 


$$
\left\{\begin{aligned}
-135^{\circ}-\delta * 10^{\circ} & <\psi<-135^{\circ}+\delta * 10^{\circ} \\
15 \mathrm{~m}-\delta * 0.5 \mathrm{~m} & <h<15 \mathrm{~m}+\delta * 0.5 \mathrm{~m} \\
20 \mathrm{~m} / \mathrm{s}-\delta * 0.5 \mathrm{~m} / \mathrm{s} & <V<20 \mathrm{~m} / \mathrm{s}+\delta * 0.5 \mathrm{~m} / \mathrm{s}
\end{aligned}\right.
$$

If ten consecutive runs were successful - i.e. if the glider could remain aloft for the whole experiment - we considered the individual as adapted to the variation rate $\delta$.

The results that were obtained indicate that the best evolved controllers were able to stand a variation rate of 9 , which means they could maintain dynamic soaring with initial conditions in the ranges:

$$
\left\{\begin{aligned}
-225^{\circ} & <\psi<-45^{\circ} \\
10,5 \mathrm{~m} & <h<19,5 \mathrm{~m} \\
15,5 \mathrm{~m} / \mathrm{s} & <V<24,5 \mathrm{~m} / \mathrm{s}
\end{aligned}\right.
$$

Concerning robustness to turbulences, the fitness function was the maximum amplitude of wind-speed perturbations tolerable to the controller. These perturbations were represented as a noise vector added to the reference wind vector. At each time step, the noise vector amplitude was modified by a random value between -0.04 and $+0.04 \mathrm{~m} / \mathrm{s}$ and its heading was modified by a random value between -0.6 and $+0.6^{\circ}$ (corresponding to a maximum change rate of $1 \mathrm{~m} / \mathrm{s} / \mathrm{s}$ and $15^{\circ} / \mathrm{s}$ ). This noise vector is added to the reference wind vector. Winds at other altitudes are then computed as stated in section 2.2, so the noise is less important at lower altitudes where the wind is slower.

Controllers able to keep the glider aloft for ten consecutive experiments with a given maximum turbulence amplitude were considered adapted to this noise level. Results indicate that the best evolved controllers were able to stand a maximum turbulence amplitude of $1.7 \mathrm{~m} / \mathrm{s}$ for a reference wind set at $20 \mathrm{~m} / \mathrm{s}$.

Finally, to assess the robustness to sensory noise, we did not use evolution. Instead, we simply tested the controller evolved in the experiment described in subsection 3.1, using a reference wind speed of $10 \mathrm{~m} / \mathrm{s}$ and adding to the sensors a gaussian noise with a zero mean and a standard deviation that was systematically varied. The results presented here correspond to the maximum standard deviation value for which ten consecutive experiments were successful, in the sense that the glider remained aloft for more than 1000 seconds:

- Maximum standard deviation for noise on altimeter: $0.09 \mathrm{~m}$

- Maximum standard deviation for noise on $\psi: 1^{o}$

- Maximum standard deviation for noise on $\theta: 1^{o}$

- Maximum standard deviation for noise on $\phi: 1.5^{\circ}$

Although such results seem to indicate that robust control requires a sensory precision that exceeds that of current off-the-shelf devices, it is still possible that this conclusion will have to be amended if more robust controllers are sought through 
improved evolutionary approaches. For instance, one could select individual able to simultaneously cope with a low and turbulent wind, on the one hand, and with noisy sensors, on the other hand. Likewise, it is still possible that more robust controllers will be generated using rules better adapted to sensory noise and environmental conditions than those that were used here.

\section{Discussion}

The main advantage of the dynamic soaring controllers described in this article is the simplicity of their design and optimization : a first controller has been hand-designed and then optimized by evolutionary algorithms. The trajectories these controllers generate are very similar to those exhibited by albatrosses above the ocean, thus demonstrating that such a natural behaviour can be implemented with few simple fuzzy-rules.

However, if they are able to keep a glider aloft in low wind conditions similar to those an albatross can cope with during dynamic soaring, these controllers can't get energy from other aerological conditions, like slope wind, which this bird is able to exploit for flying without flapping its wings. These conditions allow it to fly against the wind for example, a behaviour that the controllers studied here are unable to exhibit. To reach a performance similar to that of an albatross, several other controllers should be designed, for instance a series of low-level controllers able to exploit other aerological conditions, and a high-level controller able to switch between different behaviours, i.e. from static soaring to dynamic soaring.

Despite the fact that the apparent lack of robustness of the controllers studied here to noisy sensors, or to wind turbulence, could probably be improved with appropriate evolutionary approaches, controlling dynamic soaring is intrinsically a difficult problem because the corresponding trajectories must be very precise. In particular, when a glider flies at a few centimetres above the ocean's surface, small errors in sensors, or small wind turbulences, may be enough to make it touch the water. To help avoid such a fatal issue, robust filtering methods could be used, as well as avoidance-strategies based on optical flow that have already proved to be efficient in similar contexts [26]. Likewise, other rules could be tried that would hopefully correct the trajectory more often and more precisely.

It is also interesting to note that, if the wing aspect ratio is kept small enough, the parameters of the controllers obtained after evolution show only small differences compared to those of the reference controller. This however has a great impact on the performance of the glider, thus suggesting that the generated trajectories are very sensitive to these parameters. This renders the evolution of such a controller from scratch extremely difficult, as this process will get a substantial reward only when it is near the optimal solution. Indeed, very few solutions have a high fitness, the majority of them, especially those of the first generations, being characterized by low fitness values that cannot guide evolution. It is highly probable that, even with other sorts of controllers - e.g., neural networks - or with a different set of fuzzy rules, the same 
bootstrapping difficulty would be experienced because of the required precision in the generated trajectories.

\section{Conclusion}

Although dynamic soaring is a complex behaviour that needs to be very precisely controlled, the results that have been presented here demonstrate that it may be generated by a set of simple fuzzy rules bootstrapped by an educated guess. These results also suggest that the implementation of such rules on a real glider capitalizing on simple off-the-shelf sensors is possible, provided the corresponding platform is not used in too challenging conditions, i.e., with a too low and turbulent wind, or with too noisy sensors, and provided trajectories against the wind are not sought. Some hints for relaxing these constraints have been given in the text.

\section{Acknowledgements}

This work was supported by a BQR grant from Pierre and Marie Curie University (Paris 6). The authors wish to thank Thierry Druot for the development of the flight simulator and for his help with the analysis of the huge amount of data produced by the simulation. They also express their gratitude to the reviewers for their help in improving the manuscript.

\section{References}

[1] http://www.nongnu.org/paparazzi/.

[2] C. J. Pennycuick. The flight of petrels and albatrosses (Procellariiformes), observed in South Georgia and its vicinity. Phil. Trans. R. Soc. Lond. B, 300:75-106, 1982.

[3] R. Spaar and B. Bruderer. Migration by flapping or soaring: flight strategies of Marsh, Montagu's and Pallid Harriers in southern Israel. The Condor, 99(2):458-469, March-April 1997.

[4] N. G. Smith, D. L. Goldstein, and G. A. Bartholomew. Is long-distance migration possible for soaring hawks using only stored fat? Auk, 103(3):607-611, July-September 1986.

[5] A. Hedenström, M. Rosén, S. Åkesson, and F. Spina. Flight performance during hunting excursions in Eleonora's falcon falco eleonorae. The Journal of Experimental Biology, 202:2029-2039, 1999.

[6] J. Parle. Preliminary dynamic soaring research using a radio control glider. In 42nd AIAA Sciences Meeting and Exhibit, Reno, Nevada, 5-8 january 2004. AIAA Paper 2004-132.

[7] M. J. Allen. Autonomous soaring for improved endurance of a small uninhabited air vehicle. In 43nd AIAA Sciences Meeting and Exhibit, Reno, Nevada, 10-13 january 2005. AIAA Paper 2005-1025.

[8] M. B. E. Boslough. Autonomous dynamic soaring platform for distributed mobile sensor arrays. Technical report, Sandia National Laboratories, 2002.

[9] G. Sachs. Minimum shear wind strength required for dynamic soaring of albatrosses. Ibis, 147(1):1-10, January 2005.

[10] M. Davies. An exploratory analysis of dynamic soaring trajectories in shear layer. Technical report, Stanford University, 2004.

[11] J. Wharington. Autonomous Control of Soaring Aircraft by Reinforcement Learning. PhD Thesis, Royal Melbourne Institute of Technology, Melbourne, Australia, 1998. 
[12] J. Wharington. Heuristic control of dynamic soaring. In Proceedings of the 5th Asian Control Conference, 2004.

[13] S. Doncieux, J.B. Mouret, L. Muratet, and J.-A. Meyer. The ROBUR project: towards an autonomous flapping-wing animat. In Proceedings of the Journées MicroDrones, Toulouse, 2004.

[14] J. A. Meyer and A. Guillot. Simulation of adaptive behavior in animats: Review and prospect. In Meyer and Wilson, editors, Proceedings of The First International Conference on Simulation of Adaptive Behavior. The MIT Press, 1991.

[15] R. Von Mises. Theory of flight, chapter 7, pages 139-169. Dover Publications, Inc., 1959.

[16] R. S. Shevell. Fundamentals of flight, chapter 3, pages 51-59. Prentice Hall, second edition, 1989.

[17] K. W. Ruggles. The vertical mean wind profile over the ocean for light to moderate winds. Journal of Applied Meteorology, 9(3):389-395, 1970.

[18] R. C. Beason. Through a bird's eye - exploring avian sensory perception. Bird Strike Committee Canada, 2003.

[19] F. Hoffmann, T. J. Koo, and O. Shakernia. Evolutionary design of a helicopter autopilot. In 3rd On-Line World Conference on Soft Computing (WSC 3), 1998.

[20] I. K. Nikolos, L. Doitsidis, V. N. Christopoulos, and N. Tsourveloudis. Roll control of unmanned aerial vehicles using fuzzy logic. WSEAS Transactions on Systems, 4(2):1039-1047, 2003.

[21] E. H. Mamdani. Application of fuzzy algorithms for control of simple dynamic plants. In Institution of Electrical Engineers, 1974.

[22] T. Takagi and M. Sugeno. Fuzzy identification of systems and its application to modelling and control. In IEEE Transactions on Systems, Man and Cybernetics, volume 15. 1985.

[23] H. Shim, T. Koo, F. Hoffmann, and S. Sastry. A comprehensive study on control design of autonomous helicopter, 1998.

[24] T. Bäck and H. P. Schwefel. Evolution strategies I: Variants and their computational implementation. In Genetic Algorithms in Engineering and Computer Science, Proc. First Short Course EUROGEN-95. 1995.

[25] H. P. Schwefel and T. Bäck. Evolution strategies II: Theoretical aspects. In Genetic Algorithms iEngineering and Computer Science, Proc. First Short Course EUROGEN-95. 1995.

[26] L. Muratet, S. Doncieux, Y. Brière, and J.-A. Meyer. A contribution to vision-based autonomous helicopter flight in urban environments. Robotics and Autonomous Systems, 50(4):195-209, 2005.

\section{Appendix A. Mass characteristics of the glider}

Table A1 summarizes the mass characteristics of the glider. The solid body equations are calculated according to these values.

\section{Appendix B. Control rules evolved for different flight directions}

Table B1 specifies the rules for controllers evolved for different directions of flight relative to the wind. 


\begin{tabular}{|c|c|c|c|c|c|c|}
\hline Element & $\begin{array}{l}\text { Position (m) } \\
\text { Glider frame }\end{array}$ & Mass (kg) & $\begin{array}{c}\text { Center of gravity }(\mathrm{m}) \\
\text { Element frame }\end{array}$ & & $\begin{array}{l}\text { Inertial matrix } \\
\text { Element frame }\end{array}$ & \\
\hline Right wing (int.) & $\begin{array}{c}-0.402083 \\
0.419744 \\
-0.0146578\end{array}$ & 0.6 & $\left(\begin{array}{c}-0.0520833 \\
-9.73064 e-18 \\
-0.01875\end{array}\right)$ & $\begin{array}{c}0.0586406 \\
2.61941 e-21 \\
-0.000976563\end{array}$ & $\begin{array}{c}2.61941 e-21 \\
0.00389561 \\
1.01266 e-19\end{array}$ & $\begin{array}{c}-0.000976563 \\
1.01266 e-19 \\
0.0623956\end{array}$ \\
\hline Right wing (ext.) & $\begin{array}{c}-0.35744 \\
1.06226 \\
-0.05273 \\
\end{array}$ & 0.2 & $\begin{array}{c}-0.0385076 \\
-0.0196473 \\
-0.015557 \\
\end{array}$ & $\begin{array}{c}0.0218375 \\
-0.00217837 \\
-0.000621278 \\
\end{array}$ & $\begin{array}{c}-0.00217837 \\
0.00227367 \\
-0.000640059 \\
\end{array}$ & $\begin{array}{c}-0.000621278 \\
-0.000640059 \\
0.0240123 \\
\end{array}$ \\
\hline Left wing (int.) & $\begin{array}{l}-0.402083 \\
-0.419744 \\
-0.0146578\end{array}$ & 0.6 & $\begin{array}{c}-0.0520833 \\
-9.73064 e-18 \\
-0.01875\end{array}$ & $\begin{array}{c}0.0586406 \\
2.61941 e-21 \\
-0.000976563\end{array}$ & $\begin{array}{c}2.61941 e-21 \\
0.00389561 \\
1.01266 e-19\end{array}$ & $\begin{array}{c}-0.000976563 \\
1.01266 e-19 \\
0.0623956\end{array}$ \\
\hline Left wing (ext.) & $\begin{array}{l}-0.35744 \\
-1.06226 \\
-0.05273\end{array}$ & 0.2 & $\left.\begin{array}{c}-0.0385076 \\
0.0196473 \\
-0.015557\end{array}\right)$ & $\begin{array}{c}0.0218375 \\
0.00217837 \\
-0.000621278\end{array}$ & $\begin{array}{c}0.00217837 \\
0.00227367 \\
0.000640059\end{array}$ & $\begin{array}{c}-0.000621278 \\
0.000640059 \\
0.0240123\end{array}$ \\
\hline Tail (horiz.) & $\begin{array}{l}-1.50167 \\
0 \\
0\end{array}$ & 0.1 & $\begin{array}{c}-0.0416667 \\
5.51139 e-17 \\
-0.00625\end{array}$ & $\begin{array}{c}0.0298906 \\
-4.57276 e-19 \\
-0.000260417\end{array}$ & $\begin{array}{c}-4.57276 e-19 \\
0.002456 \\
3.01145 e-20\end{array}$ & $\begin{array}{c}-0.000260417 \\
3.01145 e-20 \\
0.032331\end{array}$ \\
\hline Tail (vert.) & $\begin{array}{c}-1.31 \\
0 \\
-0.125 \\
\end{array}$ & 0.1 & $\begin{array}{c}-0.052441 \\
-0.0203419 \\
-0.00645342 \\
\end{array}$ & $\begin{array}{c}0.00527651 \\
-0.00164927 \\
-0.000344249 \\
\end{array}$ & $\begin{array}{c}-0.00164927 \\
0.00398502 \\
-0.000179818 \\
\end{array}$ & $\begin{array}{c}-0.000344249 \\
-0.000179818 \\
0.00924467 \\
\end{array}$ \\
\hline Body & $\left(\begin{array}{l}0 \\
0 \\
0\end{array}\right.$ & 0.6 & $\begin{array}{c}-0.5225 \\
-7.08019 e-18 \\
-0.096875 \\
\end{array}$ & $\begin{array}{c}0.00368359 \\
1.75473 e-18 \\
-0.0442188 \\
\end{array}$ & $\begin{array}{c}1.75473 e-18 \\
0.31862 \\
9.09995 e-19 \\
\end{array}$ & $\begin{array}{c}-0.0442188 \\
9.09995 e-19 \\
0.317811 \\
\end{array}$ \\
\hline Propulsion & $\left(\begin{array}{l}0 \\
0 \\
0\end{array}\right.$ & 0.3 & $\begin{array}{c}-0.04 \\
-8.88112 e-19 \\
-0.0388889\end{array}$ & $\begin{array}{c}0.000259259 \\
7.08046 e-20 \\
-0.00155556\end{array}$ & $\begin{array}{c}7.08046 e-20 \\
0.00189767 \\
-1.48089 e-21\end{array}$ & $\begin{array}{c}-0.00155556 \\
-1.48089 e-21 \\
0.00189767\end{array}$ \\
\hline Technical load & $\left.\begin{array}{c}-0.15 \\
0 \\
0\end{array}\right)$ & 0.9 & $\begin{array}{c}-0.1 \\
-2.69981 e-18 \\
-0.0583333\end{array}$ & $\begin{array}{c}0.000583333 \\
1.144 e-19 \\
-0.00583333\end{array}$ & $\begin{array}{c}1.144 e-19 \\
0.011355 \\
-3.53334 e-20\end{array}$ & $\begin{array}{c}-0.00583333 \\
-3.53334 e-20 \\
0.011355\end{array}$ \\
\hline Whole glider & $\begin{array}{l}0 \\
0 \\
0\end{array}$ & 3.6 & $\begin{array}{c}-0.429336 \\
-0.000179262 \\
-0.0546229\end{array}$ & $\begin{array}{c}0.752483 \\
-3.44249 e-05 \\
-0.0854511\end{array}$ & $\begin{array}{c}-0.000164927 \\
1.00059 \\
-0.000398502\end{array}$ & $\begin{array}{c}-0.0788293 \\
0.000924467 \\
1.74149\end{array}$ \\
\hline
\end{tabular}

Table A1. Mass characteristics of the simulated glider. Element frames have the same orientation as glider frame, but they are translated by the position vector.

\begin{tabular}{|c|c|c|}
\hline & Manual controller & Controller for $8^{\circ}$ \\
\hline \multicolumn{3}{|l|}{ Fuzzy sets } \\
\hline $\mathrm{z}$ is high, Ramp bounds & $5.0 \rightarrow 13.0$ & $0.654010 \rightarrow 9.801226$ \\
\hline $\mathrm{z}$ is low, Ramp bounds & $2.0 \rightarrow 9.0$ & $2.523452 \rightarrow 12.672154$ \\
\hline \multicolumn{3}{|l|}{ Rules } \\
\hline $\mathrm{z}$ is high, $\mathrm{E}=$ & $-0.6+0.006(\psi+180)+0.01 \theta$ & $-0.595588+0.003959(\psi+180)+0.008705 \theta$ \\
\hline $\mathrm{z}$ is high, $\mathrm{G}=$ & $-1.0+0.006(\psi+180)+0.01 \varphi$ & $-2.334902+0.000483(\psi+180)+0.006289 \varphi$ \\
\hline $\mathrm{z}$ is high, $\mathrm{A}=$ & $-1.0+0.006(\psi+180)+0.007 \varphi$ & $-1.149783+0.005537(\psi+180)+0.012901 \varphi$ \\
\hline $\mathrm{z}$ is low, $\mathrm{E}=$ & $-0.8+0.005(\psi+180)+0.02 \theta$ & $-1.730784+0.000289(\psi+180)+0.016000 \theta$ \\
\hline $\mathrm{z}$ is low, $\mathrm{G}=$ & $0.0+0.006(\psi+180)+0.01 \varphi$ & $0.074608+0.007348(\psi+180)+0.009041 \varphi$ \\
\hline $\mathrm{z}$ is low, $\mathrm{A}=$ & $0.0+0.006(\psi+180)+0.007 \varphi$ & $0.001825+0.010158(\psi+180)+0.007893 \varphi$ \\
\hline
\end{tabular}

\begin{tabular}{|c|c|c|}
\hline & Controller for 30 $^{\circ}$ & Controller for 53 $^{o}$ \\
\hline Fuzzy sets & & $3.036179 \rightarrow 9.232050$ \\
\hline $\mathrm{z}$ is high, Ramp bounds & $1.514679 \rightarrow 9.579008$ & $2.521118 \rightarrow 7.275177$ \\
\hline $\mathrm{z}$ is low, Ramp bounds & & \\
\hline Rules & $-0.595588+0.004847(\psi+180)+0.008689 \theta$ & $-0.598565+0.011557(\psi+180)+0.012849 \theta$ \\
\hline $\mathrm{z}$ is high, $\mathrm{E}=$ & $-1.748078+0.004470(\psi+180)+0.009806 \varphi$ & $-0.886981+0.006102(\psi+180)+0.007703 \varphi$ \\
\hline $\mathrm{z}$ is high, $\mathrm{G}=$ & $-0.986498+0.009999(\psi+180)+0.005711 \varphi$ & $-1.135517+0.014454(\psi+180)+0.009268 \varphi$ \\
\hline $\mathrm{z}$ is high, $\mathrm{A}=$ & $-0.748618+-0.001014(\psi+180)+0.018740 \theta$ & $-0.736545+0.003373(\psi+180)+0.025652 \theta$ \\
\hline $\mathrm{z}$ is low, $\mathrm{E}=$ & $-0.004074+0.005250(\psi+180)+0.008782 \varphi$ & $-0.000016+0.006232(\psi+180)+0.010888 \varphi$ \\
\hline $\mathrm{z}$ is low, $\mathrm{G}=$ & $-0.000089+0.006423(\psi+180)+0.007393 \varphi$ & $0.000988+0.013196(\psi+180)+0.014100 \varphi$ \\
\hline $\mathrm{z}$ is low, $\mathrm{A}=$ &
\end{tabular}

Table B1. Rules of three controllers generating flights in different directions relative to the wind. Relatively small parameter changes entail quite different behaviours, as described in section 3.3 . 